\title{
Universalism of inhibitors against hydrogen sulfide and carbon dioxide corrosion of carbon steel
}

\author{
Vladimir Vigdorovich ${ }^{1}$, Liudmila Tsygankova ${ }^{1,2}$, Natalia Shel $^{1}$, and Nedal Alshikha² \\ ${ }^{1}$ All-Russian Scientific Research Institute of Use of Machinery and Oil Products, 392022, Tambov, Russia \\ ${ }^{2}$ Derzhavin State University, 392000, Tambov, Russia
}

\begin{abstract}
The universality of inhibitors is understood as their ability to inhibit several types of corrosion attack: hydrogen sulfide and carbon dioxide corrosion, hydrogen diffusion into metal, development of sulfate-reducing and other types of bacteria, negative impact on the mechanical properties of metals. Indicators of universalism of new inhibitor have been studied. Producer of the inhibiting compositions is Limited Liability Company «INCORGAZ» (S-Petersburg, Russia). The efficacy of the inhibitor in the concentration of $25-200 \mathrm{mg} / \mathrm{L}$ has been studied with respect to carbon steel in a highly mineralized chloride medium $(\mathrm{pH}=6)$ and NACE medium $\left(5 \mathrm{~g} / \mathrm{L} \mathrm{NaCl}, 0.25 \mathrm{~g} / \mathrm{L} \mathrm{CH}_{3} \mathrm{COOH}, \mathrm{pH}=3.5\right)$ containing $\mathrm{H}_{2} \mathrm{~S}$ $(50-400 \mathrm{mg} / \mathrm{L})$ and $\mathrm{CO}_{2}$ (1at) separately and together. The bactericidal properties of the inhibitor were studied with respect to sulfate-reducing bacteria in the Postgate medium. The investigations were carried out by the methods of linear polarization resistance, electrochemical impedance spectroscopy, gravimetry, potentiodynamic polarization. The protective effectiveness of the inhibitor reaches $80 \%$ in the presence of $\mathrm{CO}_{2}$ and $90 \%$ in hydrogen sulphide environments. The inhibitor repeatedly reduces the number of sulfatereducing bacteria and the production of biogenic hydrogen sulfide and inhibits the diffusion of hydrogen into steel.
\end{abstract}

\section{Introduction}

The use of inhibitors is one of the most important and widely used methods of metal protection against corrosion. One of the new areas of inhibitor protection, including in oil and gas production conditions, is the use of universal corrosion inhibitors. The universality of inhibitors is understood as their ability to inhibit several types of corrosion attack: hydrogen sulfide and carbon dioxide corrosion, hydrogen diffusion into metal, development of sulfate-reducing and other types of bacteria, negative impact on the mechanical properties of metals [1]. When developing inhibitors, a requirement is put forward by oil companies for their high efficiency at low concentrations (up to $100-200 \mathrm{mg} / \mathrm{L}$ ), at which a corrosion rate of $<0.05 \mathrm{~mm} /$ year is achieved, and a decrease in hydrogen saturation of steel equipment is observed. One of the ways to search for such inhibitors is to create compositions of substances with inhibitory properties in an individual state, in order to mutually enhance the protective properties and, thus, increase the effectiveness of anti-corrosion protection.

The aim of present paper is to study the protective efficiency of new inhibitor with respect to carbon steel in media, containing $\mathrm{H}_{2} \mathrm{~S}$ and $\mathrm{CO}_{2}$, and to evaluate its universal properties.

\section{Experimental}

Carbon steel with the following composition was used (mass \%): C 0.20; Mn 0.50; Si 0.15; P 0.04; Cr 0.30; Ni $0.20 ; \mathrm{Cu} 0.20 ; \mathrm{Fe}$ balance. Corrosion tests of carbon steel samples were carried out by weight loss method in a NACE solution $\left(5 \mathrm{~g} / \mathrm{L} \mathrm{NaCl}+0.25 \mathrm{~g} / \mathrm{L} \mathrm{CH}_{3} \mathrm{COOH}\right.$, $\mathrm{pH}=3.6)$ and a highly mineralized chloride solution $\mathrm{M} 1$ (simulation of stratum water of Samotlor oil field, $\mathrm{pH}=6$ ) with the content, g/L: $\mathrm{NaCl} 17 ; \mathrm{CaCl}_{2} 0.2 ; \mathrm{MgCl}_{2} \cdot 6 \mathrm{H}_{2} \mathrm{O}$ $0.2 ; \mathrm{NaHCO}_{3} 0.8$ containing $\mathrm{H}_{2} \mathrm{~S}(50-400 \mathrm{mg} / \mathrm{L})$ and $\mathrm{CO}_{2}$ (1at) separately and together within $24 \mathrm{~h}$. Distilled water was used, hydrochloric acid and salts were of "chemically pure" qualifications. Hydrogen sulfide was produced directly in the working solution, for which calculated amounts of $\mathrm{Na}_{2} \mathrm{~S}$ and $\mathrm{HCl}$ were introduced.

The protective effect of inhibitor $(Z)$ was calculated by the formula:

$$
\left.Z, \%=\left[\left(K_{0}-K_{i}\right) / K_{0}\right)\right] \cdot 100 \%,
$$

where $K_{0}$ and $K_{i}$ are the corrosion rates in the absence and in the presence of inhibitor in the test solutions, respectively. Temperature is ambient.

The linear polarization resistance (LPR) technique was used. Potentiodynamic polarization measurements were performed in a three-electrode cell (Pyrex) with divided anode and cathode spaces in solutions with free air access. The working electrode surface was polished with abrasive paper and degreased with acetone. A

* Corresponding author: vits21@mail.ru 
platinum counter electrode was used. The potentials were measured relative to an aqueous saturated silver/silver chloride electrode and were converted to the normal hydrogen scale. Electrochemical impedance spectroscopy (EIS) measurements (Solartron 1255 FRA and 1287 potentiostat) were carried out in the frequency range of $10 \mathrm{kHz}-50 \mathrm{mHz}$.

Investigation of the diffusion flux of hydrogen was carried out according to [2] using a two-compartment Devanathan cell separated by a steel membrane $(300 \mu \mathrm{m}$ thick, $3.63 \mathrm{~cm}^{2}$ area). The hydrogen diffusion flux was recalculated into empirical units $i_{\mathrm{H}}$. To evaluate the effect of inhibitor on the value of $i_{\mathrm{H}}$, the solid-phase diffusion coefficient was used:

$$
\gamma_{H}=i_{0, H} / i_{H}
$$

where $i_{0, \mathrm{H}}$ and $i_{\mathrm{H}}$ represent the hydrogen diffusion flux, respectively, in a non-inhibited and inhibited solution $\left(\gamma_{\mathrm{H}}\right.$ $>1$ - inhibition of the process, $\gamma_{\mathrm{H}}<1-$ stimulation of the process, $\gamma_{\mathrm{H}}=1-$ no effect).

Bactericidal properties of the compound were studied with respect to sulfate-reducing bacteria in Postgate B medium [3]. Composition of the medium was as follows, $\mathrm{g} / \mathrm{L}: \mathrm{NH}_{4} \mathrm{Cl}-1.0 ; \mathrm{K}_{2} \mathrm{HPO}_{4}-0.5 ; \mathrm{MgSO}_{4} \cdot 7 \mathrm{H}_{2} \mathrm{O}-2.0$; $\mathrm{CaSO}_{4}-1$; lactate $\mathrm{Ca}-2.6 ; \mathrm{Na}_{2} \mathrm{~S}-0.2 ; \mathrm{FeSO}_{4}(5 \%$ solution in $1 \% \mathrm{HCl})-0.5 ; \mathrm{Na}_{2} \mathrm{CO}_{3}-2$. An accumulation culture of SRB strains of Desulfomicrobium was used. The suppression coefficient of the number of SRB cells (\%) by the inhibitor studied was calculated by the ratio:

$$
\left.N=100\left[\left(n_{0}-n_{\text {Inh }}\right) / n_{0}\right)\right]
$$

where $n_{0}, n_{\text {Inh }}$ represent the number of microorganisms, respectively, in the absence and presence of an inhibitor. The efficacy of bactericidal action of the inhibitor $S(\%)$ was determined by the degree of inhibition of the vital activity of microorganisms:

$$
\left.S=100\left[\left(C_{0}-C_{I n h}\right) / C_{0}\right)\right]
$$

where $C_{0}, C_{\text {Inh }}$ represent the concentration of biogenic hydrogen sulfide, respectively, in the absence and presence of an inhibitor.

The inhibitor studied is the condensation product of tall oil fatty acids and polyamines (active form) dissolved in alcoholic solvent.

\section{Results and discussion}

The inhibitor in NACE and M1 media containing hydrogen sulfide exhibits a relatively high protective effect (Table 1 and 2).
Table 1. Corrosion rate $\left(\mathrm{K}, \mathrm{g} /\left(\mathrm{m}^{2} \mathrm{~h}\right)\right.$, numerator) and value of protective effect $(Z, \%$ denominator) of inhibitor in the NACE medium in the presence of hydrogen sulfide.

\begin{tabular}{|c|c|c|}
\hline $\begin{array}{c}\mathrm{C}_{\mathrm{H}_{2} \mathrm{~S}}, \mathrm{mg} / \mathrm{L} \\
\mathrm{C}_{\text {Inh, }} \mathrm{mg} / \mathrm{L}\end{array}$ & $\mathbf{1 0 0}$ & $\mathbf{4 0 0}$ \\
\hline 0 & 0.2083 & 0.7513 \\
\hline 25 & $0.1101 / 47$ & $0.1981 / 74$ \\
\hline 50 & $0.0926 / 55$ & $0.1136 / 85$ \\
\hline 100 & $0.0878 / 58$ & $0.1273 / 83$ \\
\hline 200 & $0.0393 / 81$ & $0.0767 / 90$ \\
\hline
\end{tabular}

In the presence of carbon dioxide, the $\mathrm{Z}$ value is $10 \%$ lower than in the presence of $\mathrm{H}_{2} \mathrm{~S}$. However, in an environment containing hydrogen sulfide and carbon dioxide at the same time, the protective effect reaches almost the same values as in the presence of hydrogen sulfide (Table 3). Moreover, in the corresponding solutions of $\mathrm{M} 1$, the value of $\mathrm{Z}$ is $3-7 \%$ higher than in NACE.

Table 2. Corrosion rate $\left(\mathrm{K}, \mathrm{g} /\left(\mathrm{m}^{2} \mathrm{~h}\right)\right.$, numerator) and value of protective effect $(\mathrm{Z}, \%$ denominator) of inhibitor in the M1 medium in the presence of hydrogen sulfide.

\begin{tabular}{|c|c|c|}
\hline $\begin{array}{c}\mathrm{C}_{\mathrm{H}_{2}} \mathrm{~s}, \mathrm{mg} / \mathrm{L} \\
\mathrm{C}_{\text {Inh, } \mathrm{mg} / \mathrm{L}}\end{array}$ & $\mathbf{1 0 0}$ & $\mathbf{4 0 0}$ \\
\hline 0 & 0.0871 & 0.4219 \\
\hline 25 & $0.027 / 69$ & $0.308 / 27$ \\
\hline 50 & $0.021 / 76$ & $0.155 / 63$ \\
\hline 100 & $0.016 / 82$ & $0.081 / 81$ \\
\hline 200 & $0.009 / 90$ & $0.043 / 90$ \\
\hline
\end{tabular}

Table 3. Corrosion rate $\left(\mathrm{K}, \mathrm{g} /\left(\mathrm{m}^{2} \mathrm{~h}\right)\right.$, numerator) and value of protective effect ( $\mathrm{Z}, \%$ denominator) of inhibitor in the NACE medium in the presence of hydrogen sulfide and carbon dioxide (1 at).

\begin{tabular}{|c|c|c|}
\hline $\begin{array}{c}\mathrm{C}_{\mathrm{H}_{2} \mathrm{~S}}, \mathrm{mg} / \mathrm{L} \\
\mathrm{C}_{\text {Inh, }} \mathrm{mg} / \mathrm{L}\end{array}$ & $\mathbf{5 0}$ & $\mathbf{4 0 0}$ \\
\hline 0 & 0.2486 & 0.7625 \\
\hline 25 & $0.092 / 63$ & $0.077 / 90$ \\
\hline 50 & $0.096 / 61$ & $0.122 / 84$ \\
\hline 100 & $0.069 / 72$ & $0.141 / 81$ \\
\hline 200 & $0.086 / 65$ & $0.061 / 92$ \\
\hline
\end{tabular}


The protective effect calculated by the formula (1) cannot be associated only with the action of the inhibitor. The fact is that in hydrogen sulfide and carbon dioxide environments, a polysulfide or carbonate film is spontaneously formed on the surface of a corrosive metal, which has a significant protective effect. Therefore, the $\mathrm{Z}$ value characterizes the integral effect of the "film-inhibitor" protective system, in which the contribution of the inhibitor does not necessarily dominate [4].

The linear polarization resistance (LPR) technique made it possible to estimate the instantaneous corrosion rate of steel and its change over time. Data obtained through this method are shown in Fig. 1. It is easy to see that in the M1 medium containing hydrogen sulfide, a systematic decrease in the corrosion rate is observed, both in the absence and in the presence of an inhibitor. In the first case, this is due to the formation of a protective film of sulfide corrosion products. In the second case, the joint effect of the "film-inhibitor" protective system is observed. A qualitatively similar picture is observed in the NACE $+\mathrm{H}_{2} \mathrm{~S}$ environment. The data in Figure 1 allow us to assess the contribution of each component of the protective system to the integral efficiency according to $[4,5]$. Data on such a differentiation of contributions to the protective system are given in Table 4.

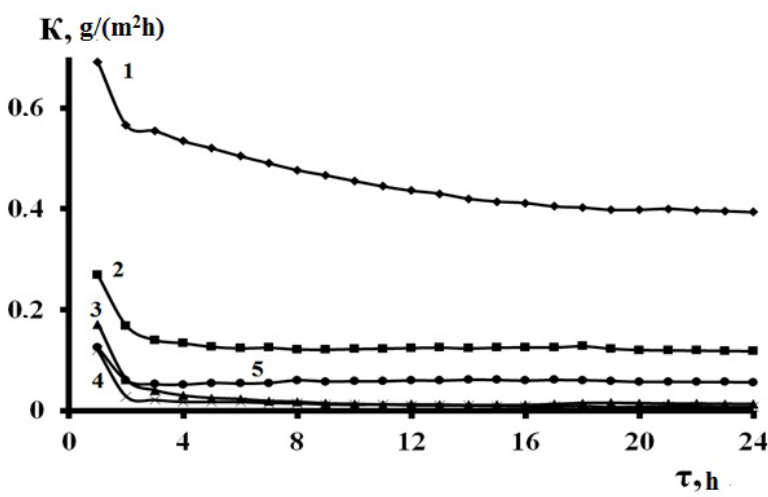

Fig. 1. The change in the instantaneous corrosion rate of steel in time in the M1 medium with $200 \mathrm{mg} / \mathrm{L}$ of hydrogen sulfide and the inhibitor with a concentration, $\mathrm{mg} / \mathrm{L}: 1-0,2-25,3-50$, 4-100, 5-200.

Table 4. The values of the contribution to the total protective effect of the film of corrosion products $\left(Z_{\text {film }}\right)$ and inhibitor (ZInh) after a $24 \mathrm{~h}$ duration in the M1 medium $+200 \mathrm{mg} / \mathrm{L} \mathrm{H}_{2} \mathrm{~S}$.

\begin{tabular}{|c|c|c|c|}
\hline $\mathrm{C}_{\text {Inh, }}, \mathrm{mg} / \mathrm{L}$ & $Z_{\text {film, }} \%$ & $\mathrm{Z}_{\Sigma}{ }^{*}, \%$ & $Z_{\text {Inh }}$ \\
\hline 50 & \multirow{3}{*}{43} & 98 & 55 \\
\hline 100 & & 99 & 56 \\
\hline 200 & & 92 & 49 \\
\hline
\end{tabular}

An analysis of the polarization curves in investigated solutions indicates that the inhibitor in both media in the presence of hydrogen sulfide slows down the anode process with a slight acceleration of the cathode one (Fig. 2).

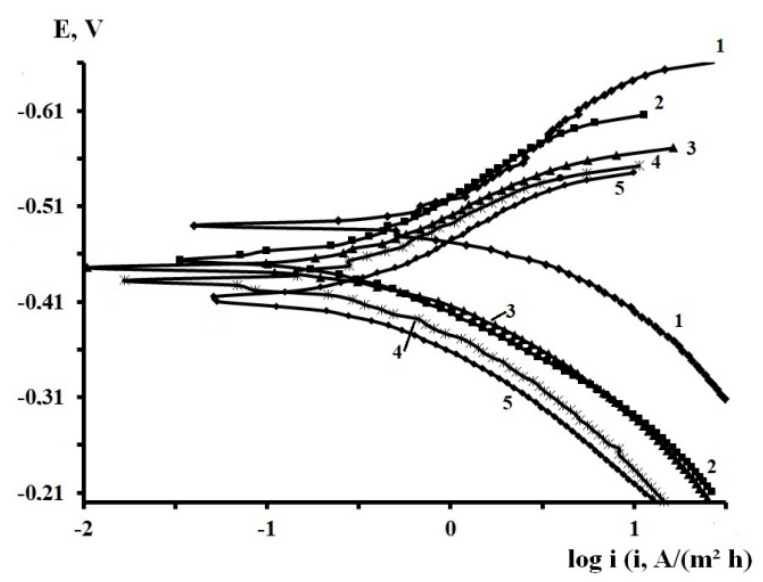

Fig. 2. Polarization curves measured on steel in NACE medium with $50 \mathrm{mg} / \mathrm{L} \mathrm{H}_{2} \mathrm{~S}$ and inhibitor with concentration, $\mathrm{mg} / \mathrm{L}: 1$ - 0; 2 - 25; 3 - 50; 4-100; 5 - 200.

Studies by impedance spectroscopy method using the equivalent circuit shown in Fig. 3, confirmed the slowdown of the anodic process by the inhibitor and its adsorption (Table 5).

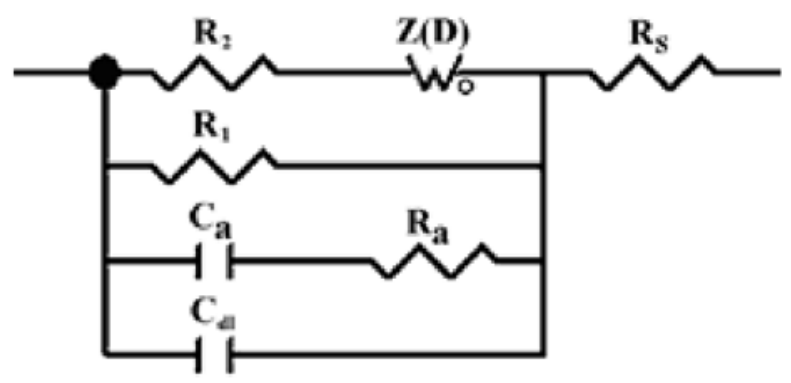

Fig. 3. Equivalent circuit that simulates the behavior of carbon steel at the corrosion potential in the studied solutions saturated with hydrogen sulfide.

In the circuit of Fig. $3, R_{\mathrm{s}}$ is the solution resistance; $R_{1}$ and $R_{2}$ are the charge transfer resistances in the anodic and cathodic reactions, respectively; $Z(\mathrm{D})$ is the generalized finite diffusion impedance of the depolarizer; the $R_{\mathrm{a}}-C_{\mathrm{a}}$ chain is related to adsorption of intermediates in the anodic process; and $C_{\mathrm{dl}}$ is the double layer capacity.

Table 5. Numerical values of some equivalent circuit elements in the NACE medium containing $400 \mathrm{mg} / \mathrm{L} \mathrm{H}_{2} \mathrm{~S}$ and the inhibitor after 6 hours of exposure of the electrode in solution.

\begin{tabular}{|c|c|c|c|}
\hline $\begin{array}{c}\mathrm{C}_{\text {Inh, } \mathrm{mg} / \mathrm{L}} \\
\text { Element }\end{array}$ & 50 & 100 & 200 \\
\hline$R_{2}, \Omega \cdot \mathrm{cm}^{2}$ & 14.20 & 10.27 & 3.85 \\
\hline$R_{1}, \Omega \cdot \mathrm{cm}^{2}$ & 407 & 783 & 2623 \\
\hline$C_{\mathrm{dl}}, \mu \mathrm{F} / \mathrm{cm}^{2}$ & 2.62 & 1.67 & 1.28 \\
\hline
\end{tabular}

A decrease in the capacitance of the electric double layer $\mathrm{C}_{\mathrm{dl}}$ with the inhibitor concentration increase 
indicates an adsorption of the inhibitor on the electrode surface.

The study of the effect of the inhibitor on the diffusion of hydrogen through a steel membrane in the process of free corrosion at a compromise potential has shown effective inhibition of the process in M1 medium containing $\mathrm{H}_{2} \mathrm{~S}$ (Table 6). Qualitatively similar results are observed in a NACE environment containing hydrogen sulfide.

Table 6. Coefficient of inhibition of hydrogen diffusion through a steel membrane by the inhibitor in the M1 medium depending on the concentration of $\mathrm{H}_{2} \mathrm{~S}$.

\begin{tabular}{|c|c|c|c|}
\hline $\begin{array}{c}\gamma_{\mathrm{H}} \text { at } \mathrm{C}_{\text {Inh, }} \\
\mathrm{mg} / \mathrm{L} \\
\mathrm{C}_{\mathrm{H} 2 \mathrm{~S}}, \mathrm{mg} / \mathrm{L}\end{array}$ & 50 & 100 & 200 \\
\hline 100 & 2.6 & 7.5 & 7.7 \\
\hline 200 & 2.6 & 4.4 & 8.9 \\
\hline 400 & 3.5 & 9.6 & 12.4 \\
\hline
\end{tabular}

The inhibitor at a concentration of $100 \mathrm{mg} / \mathrm{L}$ and more reduces the number of sulfate-reducing bacteria in Postgate medium many times (Fig. 4).

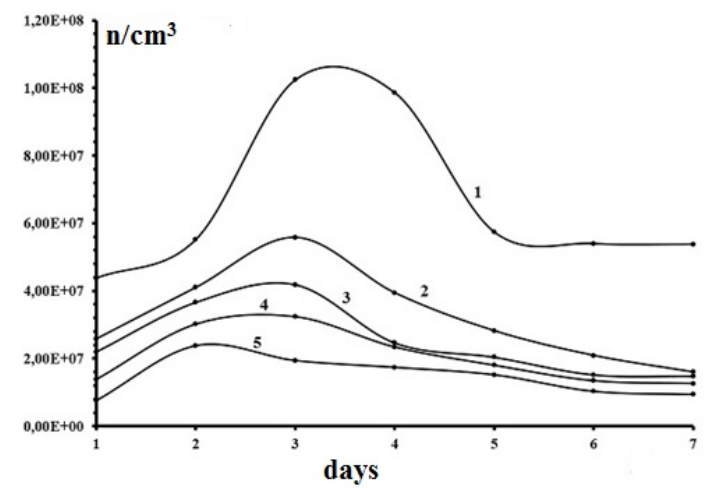

Fig. 4. SRB cell number $\left(\mathrm{n} / \mathrm{cm}^{3}\right)$ (ordinate) is a function of time (abscissa) of microorganism development in thePostgate medium without (1) and with inhibitor, $\mathrm{mg} / \mathrm{L}: 2-25,3$ - 50, 4 $-100,5-200$.

Simultaneously, the inhibitor introduced into the medium at the same concentrations, significantly suppresses the development of hydrogen sulfide as a product of the life activity of SRB (Fig. 5).

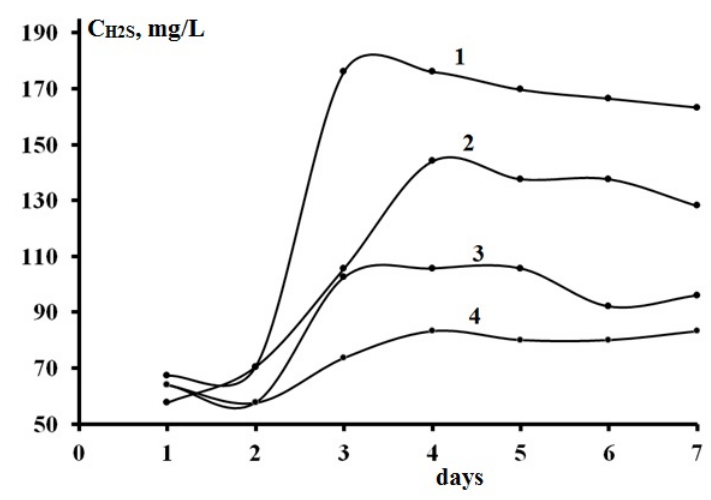

Fig. 5. Concentration of $\mathrm{H}_{2} \mathrm{~S}$ produced by SRB (ordinate) is a function of time (days) of microorganism development (abscissa) in the Postgate medium without (1) and with the inhibitor, $\mathrm{mg} / \mathrm{L}: 2-25,3-50,4-100$.

A growth of the inhibitor concentration up to 200 $\mathrm{mg} / \mathrm{L}$ decreases the quantity of biogenic hydrogen sulfide, but does not stop the reduction process completely. Probably the inhibitor under study preventing SRB reproduction in the nutrient medium cannot cease their metabolism processes completely.

Coefficients of suppression of SRB number $(\mathrm{N} / \%)$ and SRB vital activity (S/\%) are shown in Table 7 . The obtained results testify about predominately bacteriostatic action of the inhibiting compositions, which influence the enzymatic systems of SRB cells responsible directly for the sulfate reduction because of substantially decreasing the biogenic hydrogen sulfide concentration in the system.

Table 7. Coefficients of suppression of SRB number (N/\%) and SRB vital activity $(\mathrm{S} / \%)$ in the inhibitor presence (100 mg/L).

\begin{tabular}{|c|c|c|}
\hline$\tau$, days & $\mathbf{N , \%}$ & $\mathbf{S . \%}$ \\
\hline 1 & 51.5 & 4.8 \\
\hline 2 & 54.3 & 18.2 \\
\hline 3 & 67.1 & 58.2 \\
\hline 4 & 52.7 & 52.7 \\
\hline 5 & 75.1 & 52.8 \\
\hline 6 & 79.1 & 51.9 \\
\hline 7 & 79.6 & 49.0 \\
\hline
\end{tabular}

\section{Conclusion}

The considered inhibiting product is a universal corrosion inhibitor, since it significantly suppresses the corrosion of carbon steel in environments containing $\mathrm{H}_{2} \mathrm{~S}, \mathrm{CO}_{2}$ separately and together, slows down the diffusion of hydrogen into the metal, thereby contributing to the preservation of its plastic properties. This inhibitor also exhibits bactericidal properties against sulfate-reducing bacteria.

Under the studied conditions, the suppression of corrosion is carried out by the protective system "solidphase film of corrosion products (sulfide or carbonate) inhibiting additive".

The effectiveness of the protective system in hydrogen sulfide environments reaches $80-90 \%$ with a general corrosion rate of carbon steel of $0.009-0.040 \mathrm{~g} /$ $\left(\mathrm{m}^{2} \mathrm{~h}\right)$.

This work was supported by the Russian Science Foundation, grant No. 18-16-00006. 


\section{References}

1. Vigdorovich V. I., Tsygankova L. E., Inhibition of Hydrogen Sulfide and Carbon Dioxide Corrosion of Metals.Universalism of Inhibitors (KARTEK, Moscow 2011)

2. N. V. Kardash, and V. V. Batrakov, Z. Metallov, 31, 441 (1995) (Rus)

3. Postgate J.R., The Sulphate Reducing Bacteria, (2nd ed. Cambridge University Press, Cambridge, 1984)

4. V. I. Vigdorovich, L. E. Tsygankova, and N.V Shel, Surf. Interface Anal, 42, 626 (2010)

5. V. I. Vigdorovich, and S.A. Zakurnaev, Korroz.: mater., zashch. (Corros. Mater. Protect., 2, 17 2009) (Rus) 